\title{
Educational level, socioeconomic status and aphasia research: A comment on Connor et al. (2001)_Effect of socioeconomic status on aphasia severity and recovery
}

\author{
Alexandra Reis ${ }^{\mathrm{a}, \mathrm{d}, *}$ and Karl Magnus Petersson ${ }^{\mathrm{b}, \mathrm{c}, \mathrm{d}}$ \\ ${ }^{a}$ Departamento de Psicologia, Faculdade de Ciências Humanas e Sociais, Universidade do Algarve, 8000-810 Faro, Portugal \\ ${ }^{\mathrm{b}}$ Neurocognition of Language Research Group, Max Planck Institute for Psycholinguistics, Postbus 310, NL-6500 AH Nijmegen, Netherlands \\ ${ }^{\mathrm{c}}$ F.C. Donders Centre for Cognitive Neuroimaging, University of Nijmegen, Nijmegen, Netherlands \\ ${ }^{\mathrm{d}}$ Cognitive Neurophysiology Research Group R2-01, Department of Clinical Neuroscience, Karolinska Institutet, \\ Karolinska Hospital, 17176 Stockholm, Sweden
}

Accepted 22 April 2003

\begin{abstract}
Is there a relation between socioeconomic factors and aphasia severity and recovery? Connor, Obler, Tocco, Fitzpatrick, and Albert (2001) describe correlations between the educational level and socioeconomic status of aphasic subjects with aphasia severity and subsequent recovery. As stated in the introduction by Connor et al. (2001), studies of the influence of educational level and literacy (or illiteracy) on aphasia severity have yielded conflicting results, while no significant link between socioeconomic status and aphasia severity and recovery has been established. In this brief note, we will comment on their findings and conclusions, beginning first with a brief review of literacy and aphasia research, and complexities encountered in these fields of investigation. This serves as a general background to our specific comments on Connor et al. (2001), which will be focusing on methodological issues and the importance of taking normative values in consideration when subjects with different socio-cultural or socio-economic backgrounds are assessed.
\end{abstract}

(C) 2003 Elsevier Science (USA). All rights reserved.

\section{Introductory overview}

The idea that literacy is a factor affecting some aspects of the neurobiological specificity for language and other cognitive functions arose at the beginning of the previous century based on incidental and non-systematic observations. The first scientific group studies conducted with brain-damaged illiterate and literate subjects to explore these initial observations were reported in the early 1970s (for a review see Coppens, Parente, \& Lecours, 1998). However, these studies were non-conclusive and commonly did not distinguish specific effects of literacy and other more general effects of formal schooling or other relevant background factors. For instance, Cameron, Currier, and Haerer (1971) suggested that aphasia tended to be less severe and more

\footnotetext{
${ }^{*}$ Corresponding author. Fax: +351-289818560.

E-mail address: aireis@ualg.pt (A. Reis).
}

transient in illiterate subjects and suggested that the cerebral infrastructure for language is not as well localized ("planted") in the dominant hemisphere in illiterate as in literate subjects. Additional findings were interpreted as indicating a greater involvement of the right hemisphere in language processing in illiterate subjects (Lecours et al., 1988; Matute de Duran, 1986). In contrast, the findings of Damásio, Castro-Caldas, Grosso, and Ferro (1976a, 1976b) concluded that language lateralization does not depend on literacy. The interpretation of these initial results are complicated by methodological issues or the absence of essential data when we are looking to determine specific literacy or schooling effects. For example, in Cameron et al. (1971) the illiterate aphasic group had a mean education level of 2.5 years of schooling and thus may reflect illiteracy due to learning disabilities and not for specific sociocultural reasons (cf. Petersson, Reis, \& Ingvar, 2001; and Reis, Guerreiro, \& Petersson, 2001a; for a discussion of 
this issue). Further, Cameron et al. (1971) do not report the localization of the lesions or the specific nature and degree of aphasia in their study population. In the study of Matute de Duran (1986) patients of several different types of aetiologies as well as different patterns of aphasic speech disorders were pooled and not fully balanced between study groups. A potential problem with the study of Lecours et al. (1988) is that they based their neuropsychological assessment for language disorders mainly on visuographic material. They found significant differences between the normal controls and both of the left-hemisphere stroke groups, between the illiterate right-hemisphere group and the illiterate control group, but not between the literate control group and the right-hemisphere literate group. This observation prompted the authors to conclude that unschooled but not schooled subjects show visual naming difficulties after right-hemisphere involvement. However, we now know that visual naming skills assessed with line drawings are likely influenced by formal schooling and literacy (Reis, Petersson, Castro-Caldas, \& Ingvar, 2001b). Therefore, it cannot be excluded that the findings of Lecours et al. (1988) reflect pre-morbid differences between samples.

Taken together, the previously reported results are conflicting and do not allow firm conclusions to be drawn. Our preliminary conclusions based on the previous results are that: (a) there is little conclusive evidence that literacy does affect the hemispheric dominance for language organization; both illiterate as well as literate subjects present with aphasia most often after a left- and not a right-lateralized brain injury; (b) it appears, however, that the right hemisphere may have a greater role in language use in illiterate subjects; specifically, left-damaged literate subjects make a greater number of errors on some aphasia tests compared to left-damaged illiterate subjects (Lecours et al., 1988; Matute de Duran, 1986). One possible speculative interpretation of this latter finding is that the illiterate subjects may be more prone to use non-verbal strategies, in addition to language based, in different types of problem solving as suggested by for example CastroCaldas, Ferro, Guerreiro, Mariano, and Farrajota (1995). If this is the case, then the predicition would be that recovering from aphasia due to left-hemisphere lesions should have a better outcome in illiterate subjects. This have led to the study of recovery profiles of aphasia in literate and illiterate subjects. One such study (CastroCaldas et al., 1995) compared the recovery evolution in literate and illiterate subjects (all right handed, having suffered ischemic strokes affecting the left hemisphere, assessed during the same period of disease evolution and submitted to the same speech rehabilitation), using an aphasia quotient based on the characteristics of spontaneous speech, naming, oral comprehension and repetition, concluded that there were no significant differences between groups during 6 months of followup. These findings have recently been replicated (Fonseca \& Castro-Caldas, 2002). It should be noted, however, that this is a difficult research area and many factors, including socio-cultural, socio-economic, premorbid history, selectional mechanisms like different mortality rates, are difficult to control in small study samples and that there is great variability in individual recovery profiles.

During the last decade, in a related field of investigation, different studies from different cultural settings, have indicated that the prevalence of dementia is higher in poorly educated subjects, although other studies have found no or only weak evidence for such a conclusion [see for example (Bowler, Munoz, Merskey, \& Hachinski, 1998)]. There are also reports suggesting that in some circumstances the reverse can be the case, that is, indicating that less educated subjects became demented later, lived longer, and that cognitive functions declined at the same rate after dementia onset in all educational groups (Del Ser, Hachinski, Merskey, \& Munoz, 1999). Chandra et al. (1998) reported similar results indicating that dementia had a low prevalence in poorly educated populations. It appears then that the relation between educational or socio-economic status and dementia/ cognitive decline is not a straightforward simple but a complex relation presumably affected by several factors. The issue of the influence of the educational level on clinical diagnosis, prevalence, progression or severity of the cognitive decline is a complex matter and not well understood at present. It is clear that more prospective and well-designed studies are needed to further clarify these issues. This emphasizes the crucial importance of controlling potentially confounding factors (e.g., equal educational opportunities, universally available regardless of socio-economic status, ethnicity, similar premorbid medical and psychiatric history, comparable general intelligence measures, mortality rates, etc.) and matching the study groups on all relevant factors except those under investigations, indicating the complexity of this endeavour.

\section{Specific comments to Connor et al. (2001)}

In summary, the objective of Connor et al. (2001) was to determine the degree to which educational level and socio-economic status influence initial severity of aphasia and subsequent recovery in a retrospective analysis of patient records. They evaluated the records of 39 persons with aphasia: at about 4 months and 103 months post onset in a retrospective analysis. They found that early severity of aphasia to be significantly greater for subjects in the lower educational and occupational group. However, rate of recovery was the same regardless of educational or occupational status. 
The authors did not expect this last result stating that, in their terms, one may have predicted that since lower socio-economic status is linked to greater severity of aphasia in the early stages then the rate of recovery from aphasia should be lower for subjects with a lower socioeconomic status.

Connor et al. (2001) do not carefully define their concepts of educational level and occupational status (socio-economic status), neither do they report any quantification of these factors, but only their correlations, which in itself makes their results difficult to interpret. In addition, the study population is not characterized in any detail. A well-characterized definition of the population used to address these issues is crucially important for the validity of the results [for a comparable case see for example (Morais \& Kolinsky, 2000; Petersson et al., 2001; Reis et al., 2001a)]. This is also important since otherwise we run the risk of confounding factors that may have affected the cognitive outcome in this case, like formal education (high and low), illiteracy, general intelligence, learning disabilities, socio-economic, cultural, medical, or psychiatric factors. In this particular case of clinical-anatomical correlations it is important to rule out the hypothesis of a particular type of brain organization that may be responsible for learning difficulties. Moreover issues related to different selection mechanisms, for example different mortality rates between groups, were not addressed.

Connor et al. (2001) used the Boston Diagnostic Aphasia Examination to evaluate aphasia severity. In this context, it is necessary to take into consideration that evidence has been presented indicating that the educational level is a factor influencing the outcome on different aphasia testing batteries in non-lesioned populations. In other words, if pre-morbid performance levels are not taken into account then the results from investigations in lesioned populations are difficult to interpret. Normative data, related to several demographic variables including educational level, for the Boston Diagnostic Aphasia Examination are available (Borod, Goodglass, \& Kaplan, 1980; Rosselli, Ardila, Florez, \& Castro, 1990a). For example, Pineda et al. (1997) reported not only educational effects but also some effects of socio-economic factors. In addition, several researchers have addressed the topic of the influence of literacy or formal educational on several neuropsychological measures (Ardila, Rosselli, \& Rosas, 1989; Castro-Caldas, Reis, \& Guerreiro, 1997; Lecours et al., 1987; Manly et al., 1999; Ostrosky-Solís, Ardila, Rosselli, Lopez-Arango, \& Uriel-Mendonza, 1998; Reis \& Castro-Caldas, 1997; Rosselli, Ardila, \& Rosas, 1990b; Silva, Petersson, Ingvar, \& Reis, 2001). The converging result of these investigations is that health, educational, cultural, social, and occupational factors affect pre-morbid performance and if these factors are not taken into account we run the risk of observing the effects of differences in relevant background variables, instead of correctly characterizing the outcome of pathology. In other words, it is well established that it is crucially important to take for instance the educational level into account when interpreting scores on different cognitive measures, both before and after for example brain injury. In short, the diagnosis of neuropsychological syndromes using psychometric procedures potentially penalizes low-educated individuals if this is not taken into account.

The discussion above has implications for the interpretation of findings of Connor et al. (2001). The authors report an association between severity of aphasia and educational and occupational level. Since they presented the outcome of the Boston Diagnostic Aphasia Examination without explicitly taking the educational level of the subjects into account (i.e., presumably both low and high educated subjects are assessed based on the same normative values), it is a real possibility that the results of the low educated subjects are biased towards an apparently more severe speech disorder compared to the higher educated subjects. The use of psychometric instruments, if not corrected for education and other relevant factors that influence premorbid cognitive processing, may inflate the measures of the severity of the cognitive decline, in this case aphasia severity. Additional observations of Connor et al. (2001) may be important in this context, in particular that the lesion size failed to explain the differences in early or late aphasia severity ratings between high and low education and occupation groups [similar findings have been reported by Parreira et al. (1994)], and the absence of a difference in the rate of recovery. Taking the previous literature into consideration, we suggest that the results of Connor et al. (2001) can potentially be interpreted as indicating a pre-morbid difference between the study groups. At least this possibility cannot be excluded.

\section{Acknowledgments}

This work was supported in part by Fundação para a Ciência e Tecnologia (FCT/POCIT/41669/PSI/2001), EU Grant QLK6-CT-99-02140, the Swedish Medical Research council $(8276,127169)$, the Knut and Alice Wallenberg Foundation, and the Swedish Dyslexia Foundation. We thank Professor Martin Ingvar and Professor Peter Hagoort for commenting on the manuscript.

\section{References}

Ardila, A., Rosselli, M., \& Rosas, P. (1989). Neuropsychological assessment in illiterates: Visuospatial and memory abilities. Brain and Cognition, 11, 147-166. 
Borod, J. C., Goodglass, H., \& Kaplan, E. (1980). Normative data on the Boston diagnostic Aphasia examination, parietal lobe battery. Journal of Clinical and Experimental Neuropsychology, 2(3), 177189.

Bowler, J. V., Munoz, D. G., Merskey, H., \& Hachinski, V. (1998). Factors affecting the age of onset and rate of progression of Alzheimer's disease. Journal of Neurology, Neurosurgery, and Psychiatry, 65, 184-190.

Cameron, R. F., Currier, R. D., \& Haerer, A. F. (1971). Aphasia and literacy. British Journal of Disorders of Communication, 6, 161-163.

Castro-Caldas, A., Ferro, J. M., Guerreiro, M., Mariano, G., \& Farrajota, L. (1995). Influence of literacy (vs illiteracy) on the characteristics of acquired aphasia in adults. In C. K. Leong, \& R. M. Joshi (Eds.), Developmental and acquired dyslexia (pp. 79-91). Dordrecht: Kluwer Academic.

Castro-Caldas, A., Reis, A., \& Guerreiro, M. (1997). Neuropsychological aspects of illiteracy. Neuropsychological Rehabilitation, 7, $327-338$

Chandra, V., Ganguli, M., Pandav, R., Johnston, J., Belle, S., \& Dekosky, S. T. (1998). Prevalence of Alzheimer's disease and other dementias in rural India-The Indo-US study. Neurology, 51(4), $1000-1008$.

Connor, L. T., Obler, L. K., Tocco, M., Fitzpatrick, P. M., \& Albert, M. L. (2001). Effect of Socioeconomic status on aphasia severity and recovery. Brain and Language, 78, 254-257.

Coppens, P., Parente, M. A. M. P., \& Lecours, A. R. (1998). Aphasia in illiterate individuals. In P. Coppens, Y. Lebrun, \& A. Basso (Eds.), Aphasia in atypical populations (pp. 175-202). London: Lawrence Erlbaum.

Damásio, A. R., Castro-Caldas, A., Grosso, J. T., \& Ferro, J. M. (1976a). Brain specialization for language does not depend on literacy. Archives of Neurology, 33, 300-301.

Damásio, A. R., Hamsher, K., Castro-Caldas, A., Ferro, J. M., \& Grosso, J. T. (1976b). Letter to the Editor. Archives of Neurology, 33, 662 .

Del Ser, T., Hachinski, V., Merskey, H., \& Munoz, D. G. (1999). An autopsy-verified study of the effect of education on degenerative dementia. Brain, 122, 2309-2319.

Fonseca, J., \& Castro-Caldas, A. (2002). The knowledge of reading and writing rules influences aphasia outcome. Journal of the International Neuropsychological Society, 8(4), 506.

Lecours, A. R., Melher, J., Parente, M. A., Beltrami, M. C., Tolipan, L. C., \& Cary, L., et al. (1988). Illiteracy and brain damage: 3. A contribution to the study of speech and language disorders in illiterates with unilateral brain damage (initial testing). Neuropsychologia, 26, 575-589.

Lecours, A. R., Melher, J., Parente, M. A., Caldeira, A., Cary, L., \& Castro, M. J., et al. (1987). Illiteracy and brain damage: 1. Aphasia testing in culturally contrasted populations (control subjects). Neuropsychologia, 25, 231-245.

Manly, J. J., Jacobs, D. M., Sano, M., Bell, K., Merchant, C. A., \& Small, S. A., et al. (1999). Effect of literacy on neuropsychological test performance in nondemented, education-matched elders. Journal of the International Neuropsychological Society, 5(5), 191202.

Matute de Duran, E. (1986). Aphasia in Illiterates. Journal of Neurolinguistics, 2(1), 115-130.

Morais, J., \& Kolinsky, R. (2000). Biology and culture in the literate mind. Brain and Cognition, 42, 47-49.

Ostrosky-Solís, F., Ardila, A., Rosselli, M., Lopez-Arango, G., \& Uriel-Mendonza, V. (1998). Neuropsychological test performance in illiterate subjects. Archives of Clinical Neuropsychology, 13(7), $645-660$

Parreira, E., Albuquerque, L., Guerreiro, M., Leal, M.G., Farrajota, L., \& Fonseca, J., et al. (1994). Wernicke's aphasia in illiterate patients: CT scan and clinical correlation. Paper presented at the 17th Annual Meeting of the International Neuropsychological Society, Angers, France, June 1994.

Petersson, K. M., Reis, A., \& Ingvar, M. (2001). Cognitive processing in literate and illiterate subjects: A review of some recent behavioral and functional data. Scandinavian Journal of Psychology, 42, 167251.

Pineda, D. A., Rosselli, M., Ardila, A., Mejia, S. E., Romero, M. G., \& Rerez, C. (2000). The Boston Diagnostic Aphasia-Spanish version: The influence of demographic variables. Journal of the International Neuropsychological Society, 6(7), 802-814.

Reis, A., \& Castro-Caldas, A. (1997). Illiteracy: A bias for cognitive development. Journal of the International Neuropsychological Society, 3, 444-450.

Reis, A., Guerreiro, M., \& Petersson, K. M. (2001a). The influence of educational level on a neuropsychological battery. Journal of the International Neuropsychological Society, 7(4), 422-423.

Reis, A., Petersson, K. M., Castro-Caldas, A., \& Ingvar, M. (2001b). Formal schooling influences two-but not three-dimensional naming skills. Brain and Cognition, 47, 394-411.

Rosselli, M., Ardila, A., Florez, A., \& Castro, C. (1990a). Normative data on the Boston Diagnostic Aphasia Examination in a Spanishspeaking population. Journal of Clinical and Experimental Neuropsychology, 12(2), 313-322.

Rosselli, M., Ardila, A., \& Rosas, P. (1990b). Neuropsychological assessment in illiterates: II. Language and praxic abilities. Brain and Cognition, 12, 281-296.

Silva, C., Petersson, K. M., Ingvar, M., \& Reis, A. (2001). The effects of formal education on the qualitative aspects of a verbal fluency task. Journal of the International Neuropsychological Society, 7(4), 419. 